\title{
Non-Neoplastic Bone Disorder
}

National Cancer Institute

\section{Source}

National Cancer Institute. Non-Neoplastic Bone Disorder. NCI Thesaurus. Code C27572.

A non-neoplastic disorder that affects the bone or articular cartilage. 